\title{
Neuroendocrine and Cardiovascular Effects of MDE in Healthy Volunteers
}

\author{
Euphrosyne Gouzoulis, M.D., Ulrich von Bardeleben, M.D., Armin Rupp,
} Karl-Arthur Kovar, Ph.D., and Leopold Hermle, M.D.

The drug 3,4-methylenedioxyethamphetamine ([MDE] also known as "Eve") is a less toxic analog of 3,4methylenedioxymethamphetamine (also known as "Ecstasy") with similar psychotropic effects in humans. In a double-blind placebo-controlled, cross-over study we administered $140 \mathrm{mg}$ of MDE or placebo orally to eight healthy male volunteers at 1:30 P.M. Serum cortisol, prolactin (PRL), and growth hormone (GH) levels, as well as blood pressure, and heart rate were measured every 20 minutes until 5:00 P.M. Administration of MDE was followed by statistically significant long-lasting increases of serum cortisol, PRL, systolic blood pressure, and heart rate, and by a trend toward blunting of $G H$ secretion. The neuroendocrine and cardiovascular effects of MDE are comparable to those of other phenethylamines with the exception of the effect on GH secretion. [Neuropsychopharmacology 8:187-193, 1993]
KFY WORDS: MDE; MDMA; Cortisol; Prolactin; Growth hormone; Cardiovascular effects

The phenethylamines 3,4-methylenedioxymethamphetamine ([MDMA] also known as "Ecstasy") and 3,4methylenedioxyethamphetamine ([MDE] also known as "Eve") are chemically related to amphetamines and psychedelics like mescaline and methylenedioxyamphetamine (MDA) (Climko et al. 1987). However, they were purported to exert unique psychotropic effects in humans, differentiating them from the aforementioned chemically related substances (Shulgin and Nichols 1978; Shulgin 1986). Both MDMA and MDE were reported to possess antidepressant and anxiolytic properties and to evoke a well-controllable emotional experience with relaxation, peaceful feelings, increased empathy, and a drop in fear responses, mostly with-

From the Department of Psychiatry, University of Freiburg (EG, UV, LH), and Institute of Pharmaceutics, University of Tübingen (AR, K-AK), Federal Republic of Germany.

Address reprint requests: Euphrosyne Gouzoulis, M.D., Department of Psychiatry, Medical Faculty of the RWTH, Pauwelsstrasse 30, D-5100 Aachen, Federal Republic of Germany.

Received August 5, 1991; revised March 11, 1992 and June 10, 1992; accepted June 16, 1992. out distortion of sensory perception and thought and without marked stimulation (Greer and Tolbert 1986, 1990; Peroutka et al. 1988). Pharmacologic studies on the structure-activity relationships of MDMA and related compounds supported the view that MDMA and MDE might constitute a new psychoactive substance class, which was named the "entactogens" (Nichols 1986; Nichols and Oberlender 1990).

The reasons for the public controversy about MDMA are its growing popularity and illegal abuse during the past years (Seymour 1986; Beck and Morgan 1986; Beck 1990), its reported medical usefulness as an adjunct in insight-oriented psychotherapy (Grinspoon and Bakalar 1986; Greer and Tolbert 1990), and its possible neurotoxicity in humans (Price et al. 1989; Grob et al. 1990). In experimental animals, MDA and MDMA were shown to exert neurotoxic effects on central serotonergic neurons resulting in degeneration of axon terminals (Ricaurte et al. 1985, 1988; Battaglia et al. 1988b, 1990; Insel et al. 1989; Gibb et al. 1990; Schmidt et al. 1990). It is not yet clear whether this finding has a relevance for humans (Peroutka et al. 1987; Price et al. 1989; Grob et al. 1990), but it played an important role for the assignment of MDMA to Schedule I status by the Drug Enforcement Agency in 1985. After the 
scheduling of MDMA its N-ethyl analog, MDE ("Eve"), became more popular and served as an MDMA substitute for recreational use (Beck 1990). The action of MDE is supposed to be more subtle and shorter ( 3 to 4 hours), but otherwise very similar to the action of MDMA. Studies of animal behavior underlined the similarity between MDE and MDMA (Boja and Schechter 1987). Neurochemical studies showed that MDE is farless toxic than MDA and MDMA (Schmidt 1987; Ricaurte et al. 1987; Stone et al. 1987; Gibb et al. 1990).

Both MDMA and MDE show high affinities at serotonin (5-HT) uptake sites, and lower affinities at norepinephrine and dopamine (DA) uptake sites of central neurons (Battaglia et al. 1988a). They are taken up into the neurons and cause release and reuptake inhibition of the endogenous transmitters (Johnson et al. 1986,1988; Steele et al. 1987; Schmidt 1987). In addition, the substances have low affinities at $5-\mathrm{HT}_{2^{-}}$, $5-\mathrm{HT}_{1^{-}}$, and $\mathrm{D}_{2}$-binding sites, but those seem to be less important for the drugs' action (Lyon et al. 1986; Battaglia et al. 1988a).

In our literature review, we found only anecdotal reports about the psychotropic effects and no human experimental data on neurobiologic effects of the drugs. The aim of our investigation was to study the pharmacokinetics and metabolism, as well as the psychologic and neurobiologic effects (endocrine, polysomnographic, cardiovascular) of MDE in healthy volunteers, and to attempt a characterization of the substance. In this paper, we present the neuroendocrine and cardiovascular studies.

Studies of the neuroendocrine effects of centrally acting drugs may contribute to the pharmacologic characterization of these substances. Numerous studies demonstrate that 5-HT and 5-HT agonists stimulate hypothalamic neurons that regulate adrenocorticotropic hormone and corticosterone secretion from the pituitary and adrenocortex, respectively (Fuller 1981). The secretion of prolactin (PRL) from the anterior pituitary is regulated by inhibitory tuberoinfundibular dopaminergic neurons and by an indirect stimulatory serotonergic mechanism (Gudelsky 1981; Van de Kar et al. 1985a). The secretion of growth hormone $(\mathrm{GH})$ is stimulated by enhanced catecholaminergic and serotonergic transmission (Brown et al. 1978; Matussek 1988; Meltzer and Nash 1988). Both MDMA and MDE provoke release and reuptake inhibition of 5-HT in the central nervous system (CNS), and to a lesser extent also of norepinephrine and dopamine (Johnson et al. 1986,1988; Steele et al. 1987). Thus, one might expect that the acute administration of MDMA or MDE in healthy volunteers would increase the secretion of corticosterone, $\mathrm{GH}$, and probably PRL, resulting in elevated plasma levels. Such findings would also be in line with animal experimental data showing an enhancement of cortisol and PRL secretion induced by MDMA (Nash et al. 1988).

\section{MATERIALS AND METHODS}

\section{Subjects}

Eight physically and mentally healthy, drug-free, male volunteers (all academics: seven physicians, one engineer), ranging in age from 29 to 50 years (mean 38 years) were included in a randomized double-blind placebo-controlled cross-over study. They gave informed written consent and did not receive any payment for participating in the study. Three to 7 days prior to the trial they underwent extensive physical and mental examinations (medical history, physical examination, electroencephalography, electrocardiography (ECG), free psychiatric interview, structured clinical interview according to DSM-III-R, Freiburger Personality Inventory (FPI), State-Trait Anxiety Inventory $X_{2}$, and a questionnaire for vegetative lability). The exclusion criteria were any significant physical illness requiring therapy, any mental illness, and alcohol or substance abuse at present or in the past, as defined by DSM-III criteria. Mental illness in frrst degree relatives was also an exclusion criterion. No volunteer had previous experience with MDE. One subject reported one experience with MDMA 2 years before. Another subject reported sporadic experience with cannabis about 10 to 15 years before, and one experience with MDMA 1.5 years before. A third subject reported sporadic experience with cannabis and one experience with D-lysergic acid (LSD) about 7 to 10 years before. All psychometric measurements were within normal range, except for the FPI dimension "openness," in which a higher than average mean score was obtained. The complete psychometric data are reported in a separate paper (Hermle et al., 1993).

\section{Substances}

The MDE used in this study was synthesized at theInstitute of Pharmaceutics, University of Tübingen and was obtained in the form of $70 \mathrm{mg}$ capsules. Placebo capsules were obtained from the same institute. The volunteers received $140 \mathrm{mg}$ of $\mathrm{MDE}$, a dose commonly taken for recreational use (Greer and Strassman 1985; Beck and Morgan 1986; Seymour 1986; Peroutka 1990).

\section{Experimental Design}

Subjects arrived at the hospital at 12:00 A.M. They received a standardized calorie- and electrolyte-balanced diet for lunch, and then entered the laboratory. Subjects had to stay awake and supine with head and upper trunk elevated on a bed in a single sound-isolated room during the trial while they were observed by a video camera with a monitor located in the neighboring laboratory unit. An intravenous catheter was placed in a forearm vein between 1:15 P.M. and 1:25 P.M. and 
was kept open during the trial by a slow infusion of saline solution. The cuff of the sphygmomanometer and ECG rate meter for registration of blood pressure and heart rate was placed round the other forearm. The catheter and the sphygmomanometer were connected to long tubes that passed through an opening in the wall into the adjacent laboratory. The taking of blood samples and cardiovascular measurements were performed in the laboratory room. Either MDE or placebo was given orally with some liquid at 1:30 P.M. Blood samples for the determination of serum cortisol, PRL, and $\mathrm{GH}$ concentrations, as well as for the determination of the $\mathrm{MDE}$ concentration were drawn every 20 minutes from 2:00 to 5:00 P.M. Blood samples for the determination of cortisol were drawn into $10 \mathrm{ml}$ heparinized tubes $(150 \mu \mathrm{l}$ heparin solution, $\mathrm{C}=125 \mathrm{IE} / \mathrm{ml})$. Blood samples for determination of $\mathrm{GH}$ and PRL were drawn into $10 \mathrm{ml}$ Trasylol and ethylenediaminetetraacetic acid (EDTA)-treated tubes ( $150 \mu \mathrm{l}$ Trasylol solution, $\mathrm{C}=333$ $\mathrm{KIE} / \mathrm{ml}, 250 \mu \mathrm{l}$ EDTA solution, $\mathrm{C}=1 \mathrm{mg} / \mathrm{ml}$ ). Blood samples were centrifuged immediately after drawing at $+4^{\circ} \mathrm{C}, 4000 \mathrm{U} / \mathrm{min}$, for 10 minutes. Serum was separated, transferred to glass tubes, and stored at $-70^{\circ} \mathrm{C}$ until the time of assay. The subjects were examined for heart rate and blood pressure every 20 minutes from 2:00 P.M. to 5:00 P.M. After the end of the trial subjects remained in the hospital for another 2 to 3 hours and were monitored clinically and cardiovascularly. If necessary, transportation home was arranged for them, and astaff member stayed with them until the next day. The second trial (placebo/MDE) was performed 1 to 4 weeks after the first trial.

The investigation was part of a pilot study on psychologic and neurobiologic effects of MDE on normal control subjects and was performed in accordance with the requirements of the Declaration of Helsinki. The study was approved by the local ethics committee of the University of Freiburg. In addition to the above described neuroendocrine and cardiovascular tests the volunteers participated in a series of psychometric tests, which were performed before ingestion of the drug, and at 2,5, and 24 hours after ingestion of the drug, as well as7 days after the trial. Pharmacokinetics and metabolism of the drug were investigated in the blood and urine samples of the subjects at the Institute of Pharmaceutios, University of Tübingen. Evaluation of the pharmaceutical/toxicological data is currently in progress. The psychometric data are reported in a separate paper (Hermle et al., 1993).

\section{Hormone Determinations}

Serum concentrations of cortisol, PRL, and GH were measured using commercial kits. Cortisol was measured by the solid face method with 125J-Cortisol (Gam- macoat, Dade). Concentrations of PRL and GH were measured by immunoradiometric assays (Irma, IDS). The coefficients of variation were as follows. For cortisol: 4.4 to 7.9 (within assay) and 5.2 to 9.7 (between assay); for PRL 2.7 to 4.8 (within assay) and 3.9 to 7.3 (between assay); and for GH 3.7 to 5.7 (within assay) and 9.7 to 11.4 (between assay).

\section{Statistical Analysis}

Mean values and standard deviation (SD) were calculated for all data. The time course of hormone concentration and cardiovascular data were analyzed by multivariate analysis of variance (MANOVA) with repeated measurements. Further analysis was performed with two-tailed Student's $t$-tests, followed by the Bonferroni procedure. Statistically significant $p$ values were considered to be those less than 0.05 .

\section{RESULTS}

\section{Neuroendocrine Data}

Following placebo administration, cortisol and PRL levels were stable, except for a slight decrease in plasma cortisol during the registration period, which was interpreted as relief from stress. Significant long-lasting increases in serum cortisol and PRL were produced by MDE (MANOVA, $p=.001$ and .0197, respectively). Following placebo administration, four of the eight volunteers showed one or two secretion peaks for GH during the registration period. Following MDE administration the $\mathrm{GH}$ level remained stable in all volunteers during the entire registration period. However, the resulting difference in GH levels after MDE and placebo, indicating a blunting of $\mathrm{GH}$ secretion after MDE administration, was not statistically significant (MANOVA, $p=$ .0870). The neuroendocrine data are shown in Figure 1 ( $t$-test, Bonferroni procedure).

\section{Cardiovascular Data}

Blood pressure and heart rate remained stable after placebo administration. Long-lasting increases in systolic blood pressure and heart rate were produced by MDE (MANOVA, $p=.006$ and .001, respectively). The increase in diastolic blood pressure after MDE administration was not statistically significant (MANOVA, $p=$ .053). The cardiovascular data are shown in Figure 2 ( $t$-test, Bonferroni procedure).

\section{DISCUSSION}

Oral administration of $140 \mathrm{mg}$ of MDE to eight healthy male volunteers was followed by significant increases 

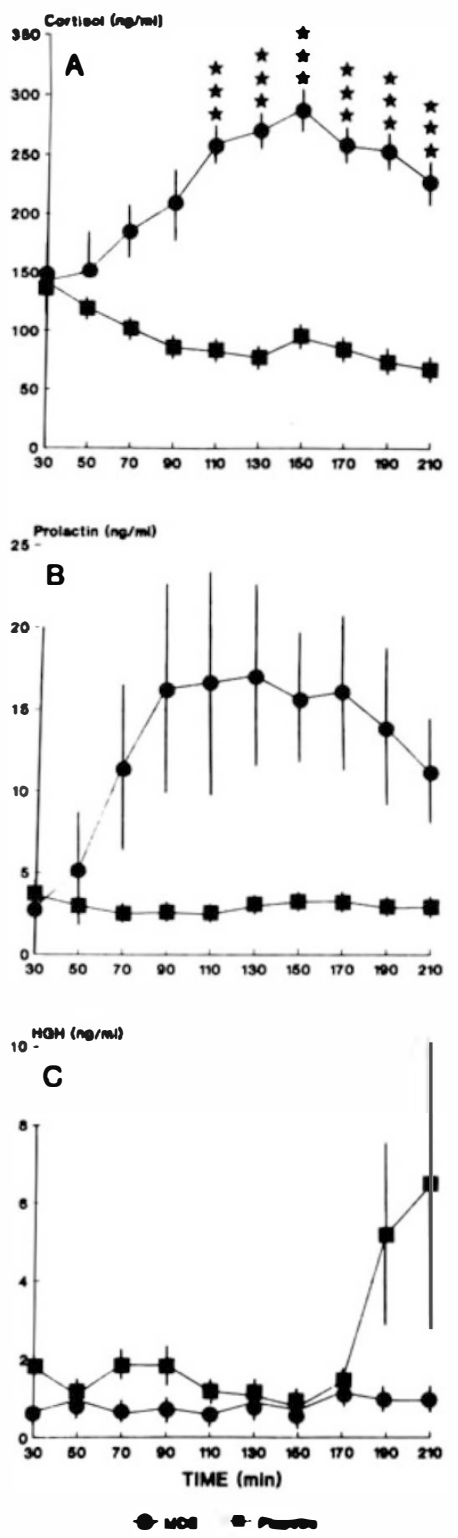

Figure 1. The effects of $140 \mathrm{mg}$ MDE or placebo on serum levels of cortisol (A), prolactin (B), and growth hormone $(\mathrm{HGH})(\mathrm{C})$ in eight healthy male volunteers $(\overline{\mathrm{x}}$ and SD; $t$-test; Bonferroni procedure: " $\left.p<.05 ;{ }^{* *} p<.01 ;{ }^{* * *} p<.001\right)$. Time $0=\mathrm{MDE} /$ placebo administration.

in plasma cortisol and PRL concentrations and a trend toward decrease of GH secretion.

A probable explanation for the effects of MDE on plasma cortisol and PRL levels might be an indirect serotonergic mechanism. This would be in line with experimental data from animal studies. In vitro studies on rat brain slices showed that MDMA and MDE evoke release and inhibit reuptake of endogenous 5-HT and catecholamines, the preferential effects being on the serotonergic, and the weakest effects on the DA systems (Johnson et al. 1986; Steele et al. 1987; Battaglia et al. 1988a). Serotonin and norepinephrine are known
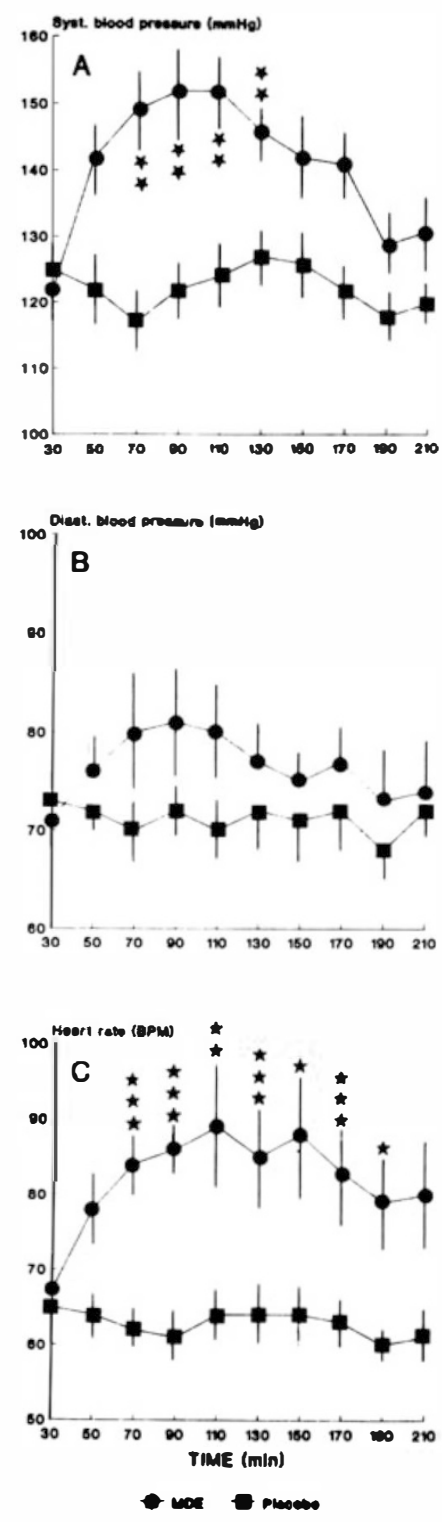

Figure 2. The effects of $140 \mathrm{mg}$ MDE or placebo on systolic blood pressure (A), diastolic blood pressure (B), and heart rate $(C)$ in eight healthy male volunteers $(\bar{x}$ and SD; $t$-test; Bonferroni procedure: " $\left.p<.05 ;{ }^{* *} p<.01 ;{ }^{* * *} p<.001\right)$. Time $0=\mathrm{MDE} /$ placebo administration.

to stimulate the secretion of cortisol and PRL (Laakmann 1990; Matussek 1988; Meltzer and Nash 1988). Nash et al. (1988) and Nash and Meltzer (1990) showed that MDMA stimulates the secretion of cortisol and PRL in the rat. In those studies the effect of MDMA on cortisol secretion was clearly shown to be mediated via serotonergic mechanisms, as it was blocked or blunted by $5-\mathrm{HT}_{2}$ antagonists or pretreatment with fluoxetine or p-chlorophenylalanine. The mechanism mediating PRL secretion could not be entirely clarified; however, the authors of that case hypothesized that a serotonergic mechanism was responsible, because the effect was 
blunted after pretreatment with p-chlorophenylalanine. They came to the conclusion that MDMA requires endogenous 5-HT to stimulate the secretion of PRL and corticosterone (Nash et al. 1988). In studies with other amphetamine derivatives similar effects on plasma cortisol and PRL were also demonstrated (Mc Elroy et al. 1984; Van de Kar et al. 1985a, b). Finally, the phenethylamine psychedelic mescaline and the indole psychedelic $\mathrm{N}, \mathrm{N}$-dimethyltryptamine (N,N-DMT), which act via 5-HT-dependent mechanisms, were also shown to incease plasma PRL (Demisch and Neubauer 1979; Meltzer et al. 1978, 1981).

In contrast, the observed trend toward a decrease of serum GH following MDE administration is difficult to interpret. To our knowledge, there are no previous experimental data on the effect of MDMA or MDE on $\mathrm{CH}$ secretion. However, a substance enhancing release of endogenous 5-HT and catecholamines and acting as a direct 5-HT agonist would be expected to cause augmentation of GH secretion (Brown et al. 1978; Laakmann 1990; Meltzer and Nash 1988). The increase of $\mathrm{CH}$ plasma levels was demonstrated in numerous studies following administration of amphetamines (Besser et al. 1969; Parkes et al. 1977) and the hallucinogenic substances mescalin, N,N-DMT, and LSD (Demisch and Neubauer 1979; Meltzer et al. 1981). The observed trend toward blunting of GH secretion following MDE administration in our study might indeed support the hypothesis of a novel psychoactive substance class (Nichols 1986). However, this effect was not statistically signifcant. Further studies are needed to better assess this potentially interesting finding.

The cardiovascular effects of MDE with long-lasting significant rises in blood pressure and heart rate underline its sympathomimetic properties. Similar sympathomimetic effects were reported in a human pilot study (Downing 1986) after ingestion of MDMA and were frequently observed with the use of amphetamine and derivatives (Turek et al. 1974; Angrist et al. 1987). As in the study of Downing (1986), the volunteers had no particular discomfort or awareness of the altered cardiovascular parameters, and mostly felt calm and relaxed (unpublished data of the psychometric tests). The cardiovascular effects of MDE might be mediated via indirect catecholaminergic mechanisms (release and reuptake inhibition of norepinephrine).

In conclusion, the neuroendocrine and cardiovascular effects of MDE in normal control subjects were similar to the effects of other amphetamines and chemically related hallucinogens, as previously reported in the literature. The trend toward blunting of GH secretion is perhaps an exception in this respect and is a potentially interesting finding, but it was not statistially significant. Evaluation of the data derived from our studies on the subjective and polysomnographic effects of $\mathrm{MDE}$ in healthy volunteers also stresses the similarities of MDE to stimulant amphetamines: in these studies a marked overall stimulation with increased vigility was shown to be the most robust effect of MDE. Also in those studies we found some potentially interesting trends (nonsuppression of slow-wave-sleep, simultaneous appearance of increased psychomotor drive, subjective feelings of relaxation, diminished anxiety, and depressed mood), that might indicate unique effect patterns of MDE, but those findings also did not reach statistical significance (unpublished data). Further investigations are needed in order to assess the neurobiologic and subjective effects of MDE and related substances and thus contribute to the pharmacologic characterization of the "entactogens."

\section{REFERENCES}

Angrist B, Corwin J, Bartlik B, Cooper T (1987): Early pharmacokinetics and clinical effects of oral d-amphetamine in normal subjects. Biol Psychiatry 22:1357-1368

Battaglia G, Brooks BP, Kulsakdinum C, DeSouza EB (1988a): Pharmacologic profile of MDMA (3,4-methylenedioxymetamphetamine) at various brain recognition sites. Eur J Pharmacol 149:159-163

Battaglia G, Yeh SY, DeSouza EB (1988b): MDMA-induced neurotoxicity: Parameters of degeneration and recovery of brain serotonin neurons. Pharmacol Biochem Behav 29:269-274

Battaglia G, Zaczek R, DeSouza EB (1990): MDMA effects in brain: Profile and evidence of neurotoxicity from neurochemical and autoradiographic studies. In Peroutka SJ (ed), Ecstasy: The Clinical, Pharmacological and Neurotoxicological Effects of the Drug MDMA. Boston, Kluwer, pp 171-199

Beck J (1990): The public health implications of MDMA use. In Peroutka SJ (ed), Ecstasy: The Clinical, Pharmacological and Neurotoxicological Effects of the Drug MDMA. Boston, Kluwer, pp 77-103

Beck J, Morgan PA (1986): Designer drug confusion: A focus on MDMA. J Drug Educ 1:287-303

Besser GM, Butler PWP, Laudon J, Rees L (1969): Influence of amphetamines on plasma corticosteroid and growth hormone levels in man. Br J Med 4:528-530

Boja JW, Schechter M (1987): Behavioral effects of N-ethyl3,4-methylenedioxyamphetamine (MDE; "Eve"). Pharmacol Biochem Behav 28:153-156

Brown GM, Seggie JA, Chambers JW, Ettigi PG (1978): Psychoendocrinology and growth hormone: a review. Psychoneuroendocrinology 3:131-153

Climko RP, Roehrich H, Sweeney DR, Al-Razi J (1987): Ecstasy: A review of MDMA and MDA. Int J Psychiatry Med 16:359-372

Demisch L, Neubauer M (1979): Stimulation of human prolactin secretion by mescaline. Psychopharmacology 64:361363

Downing J (1986): The psychological and physiological effects of MDMA on normal volunteers. J Psychoactive Drugs 18:335-340 
Fuller RW (1981): Serotonergic stimulation of pituitary-adrenocortical function in rats. Neuroendocrinology 32: 118-127

Gibb JW, Stone D, Johnson M, Hanson GR (1990): Neurochemical effects of MDMA. In Peroutka SJ(ed), Ecstasy: The Clinical, Pharmacological and Neurotoxicological Effects of the Drug MDMA. Boston, Kluwer, pp 133-150

Greer G, Strassman RJ (1985): Information on "Ecstasy." Am J Psychiatry 142:1391

Greer G, Tolbert R (1986): Subjective reports of the effects of MDMA in a clinical setting. J Psychoactive Drugs 18:319-327

Greer G, Tolbert R (1990): The therapeutic use of MDMA. In Peroutka SJ (ed), Ecstasy: The Clinical, Pharmacological and Neurotoxicological Effects of the Drug MDMA. Boston, Kluwer, pp 21-35

Grinspoon L, Bakalar JM (1986): Can drugs be used to enhance the psychotherapeutic process? Am J Psychother XL:393-404

Grob C, Bravo G, Walsh R (1990): Second thoughts on 3,4methylenedioxymethamphetamine (MDMA) neurotoxicity. Arch Gen Psychiatry 47:288

Gudelsky GA (1981): Tuberoinfundibular dopamine neurons and the regulation of prolactin secretion. Psychoneuroendocrinology 6:3-16

Hermle L, Spitzer M, Borchardt D, Kovar KA, Gouzoulis E (1993): Psychological effects of MDE in normal subjects: Are entactogens a new class of psychoactive agents? Neuropsychopharmacology 8:171-176

Insel R, Battaglia G, Johannessen JN, Marra S, De Souza EB (1989): 3,4-Methylenedioxymetamphetamine ("Ecstasy") selectively destroys brain serotonin terminals in rhesus monkeys. J Pharmacol Exp Ther 249:713-720

Johnson MP, Hoffman AJ, Nichols DE (1986): Effects of the enantiomers of MDA, MDMA and related analogues on $\left[{ }^{3} \mathrm{H}\right]$ serotonin and $\left[{ }^{3} \mathrm{H}\right]$ dopamine release from superfused rat brain slices. Eur J Pharmacol 132:269-276

Johnson M, Letter AA, Merchant K, Hanson GR, Gibb JW (1988): Effects of 3,4-methylenedioxyamphetamine and 3,4-methylenedioxymetamphetamine isomers on central serotonergic, dopaminergic and nigral neurotensin systems of the rat. J Pharmacol Exp Ther 244:977-982

Laakmann G (1990): Psychopharmacoendocrinology and Depression Research. Berlin, Springer-Verlag

Lyon RA, Glennon RA, Titeler M (1986): 3,4-methylenedioxymethamphetamine (MDMA): Stereoselective interactions at brain 5-HT1 and 5-HT2 receptors. Psychopharmacology 88:525-526

Matussek N (1988): Catecholamines and mood: Neuroendocrine aspects. In Ganten D, Pfaff D (eds), Neuroendocrinology of Mood. Berlin, Springer-Verlag, pp 141-181

Mc Elroy JF, Miller JM, Meyer JS (1984): Fenfluramine, p-chloroamphetamine and p-fluoroamphetamine stimulation of pituitary-adrenocortical activity in rat: Evidence for differences in site and mechanism of action. J Pharmacol Exp Ther 228:593-599

Meltzer HY, Nash JF (1988): Serotonin and mood. Neuroendocrine aspects. In Ganten D, Pfaff D (eds), Neuroendocrinology of Mood. Berlin, Springer-Verlag, pp 183-210

Meltzer HY, Fessler RG, Simonovic M, Fang VS (1978): The effect of mescaline, 3,4-dimethoxylphenethylamine and 2,5-dimethoxy-4-methylamphetamine on rat plasma prolactin: evidence for serotonergic mediation. Life Sci 23:1185-1192

Meltzer HY, Simonovic M, Fang VS, Goode DJ (1981): Neuroendocrine effects of psychotomimetic drugs. J McLean Hosp 6:115-137

Nash JF, Meltzer HY (1990): Neuroendocrinological effects of MDMA in the rat. In Peroutka SJ (ed), Ecstasy: The Clinical, Pharmacological and Neurotoxicological Effects of the Drug MDMA. Boston, Kluwer, pp 225-239

Nash JF, Meltzer HY, Gudelsky GA (1988): Elevation of serum prolactin and corticosterone concentrations in the rat after administration of 3,4-methylenedioxymethamphetamine. J Pharmacol Exp Ther 245:873-879

Nichols DE (1986): Differences between the mechanism of action of MDMA, MBDB, and the classic hallucinogens. Identification of a new therapeutic class: Entactogens. J Psychoactive Drugs 18:305-313

Nichols DE, Oberlender R (1990): Structure-activity relationships of MDMA and related compounds: a new class of psychoactive agents? In Peroutka SJ (ed), Ecstasy: The Clinical, Pharmacological and Neurotoxicological Effects of the Drug MDMA. Boston, Kluwer, pp 105-131

Parkes JD, Debono AG, Jenner P, Walters J (1977): Amphetamines, growth hormone and narcolepsy. Br J Clin Pharmacol 4:343-349

Peroutka SJ (1990): Recreational use of MDMA. In Peroutka SJ (ed), Ecstasy: The Clinical, Pharmacological and Neurotoxicological Effects of the Drug MDMA. Boston, Kluwer, pp 53-62

Peroutka SJ, Pascoe N, Faull KF (1987): Monoamine metabolites in the cerebrospinal fluid of recreational users of 3,4 methylenedimethoxymethamphetamine (MDMA; "Ecstasy' $\left.^{\prime \prime}\right)$. Res Commun Subs Abuse 8:125-138

Peroutka SJ, Newman H, Harris H (1988): Subjective effects of 3,4-methylenedioxymethamphetamine in recreational users. Neuropsychopharmacology 1:273-277

Price LH, Ricaurte GA, Krystal JH, Heninger GR (1989): Neuroendocrine and mood responses to intravenous L-Tryptophan in 3,4-methylenedioxymethamphetamine (MDMA) users. Arch Gen Psychiatry 46:20-22

Ricaurte G, Bryan G, Strauss L, Seiden L, Schuster C (1985): Hallucinogenic amphetamine selectively destroys brain serotonin nerve terminals. Science 229:986-988

Ricaurte G, Finnegan KF, Nichols DE, De Lanney LE, Irwin I, Langston JW (1987): 3,4-Methylenedioxyethylamphetamine (MDE), a novel analogue of MDMA, produces longlasting depletion of serotonin in the rat brain. Eur J Pharmacol 137:265-268

Ricaurte G, De Lanney LE, Irwin I, Langston JW (1988): Toxic effects of MDMA on central serotonergic neurons in the primate: importance of route and frequency of drug administration. Brain Res 446:165-168

Schmidt CJ (1987): Acute administration of methylenedioxymetamphetamine: comparison with the neurochemical effects of its $\mathrm{N}$-desmethyl and $\mathrm{N}$-ethyl analogs. Eur J Pharmacol 136:81-88

Schmidt CJ, Taylor VL (1990): Neurochemical effects of methylenedioxymethamphetamine in the rat: acute versus long-term changes. In Peroutka SJ(ed), Ecstasy: The Clin- 
ical, Pharmacological and Neurotoxicological Effects of the Drug MDMA. Boston, Kluwer, pp 151-169

Seymour RB (1986): MDMA. San Francisco, Haight-Ashbury Publications

Shulgin AT (1986): The background and chemistry of MDMA. J Psychoactive Drugs 18:291-304

Shulgin AT, Nichols DE (1978): Characterization of three new psychotomimetics. In Stillman RC, Willette RE (eds), The Psychopharmacology of Hallucinogens. New York, Pergamon Press, pp 74-83

Steele TD, Nichols DE, Yim GKW (1987): Stereochemical effects of 3,4-methylenedioxymetamphetamine (MDMA) and related amphetamine derivatives on inhibition of uptake of $\left[{ }^{3} \mathrm{H}\right]$ monoamines into synaptosomes from different regions of rat brain. Biochem Pharmacol 36:2297-2303

Stone DM, Johnson M, Hanson GR, Gibb GW (1987): A com- parison of the neurotoxic potential of methylenedioxyamphetamine (MDA) and its $\mathrm{N}$-methylated and $\mathrm{N}$-ethylated derivatives. Eur J Pharmacol 134:245-248

Turek IS, Soskin RA, Kurland AA (1974): Methylenedioxyamphetamine (MDA): Subjective effects. J Psychedelic Drugs 6:7-14

Van de Kar LD, Karteszi M, Bethea CL, Ganong WF (1985a): Serotonergic stimulation of prolactin and corticosterone secretion is mediated by different pathways from the mediobasal hypothalamus. Neuroendocrinology 41: 380-384

Van de Kar LD, Urban JH, Richardson KD, Bethea CL (1985b): Pharmacological studies on the serotonergic and nonserotonin-mediated stimulation of prolactin and corticosterone secretion by fenfluramine. Neuroendocrinology 41:283-288 